\title{
Beginning and Capping Undergraduate Education
}

\author{
Libby V. Morris
}

Published online: 30 March 2014

(C) Springer Science+Business Media New York 2014

In fall semester 2011, the University of Georgia undertook a comprehensive program to introduce all first-year students to college life through a required, one-credit hour seminar. Named the First-Year Odyssey (FYO), the goals include introducing students to the academic culture of the university in the first weeks of college, providing each student with a faculty-led, small seminar (15-18 students) in the first term and introducing students to the multiple missions of the university and the wide range of disciplines and fields open for study (https:// fyo.uga.edu/about.html). Indeed, we believe that we can make a difference in the college experience for incoming students through this deliberate focus on academics and the broad range of curricular and co-curricular opportunities in the first days of college life.

More than 300 seminars are offered each fall (and a few in the spring semester) to accomplish these goals and to ensure $100 \%$ participation by all beginning students. Multiple meetings across many months were devoted to considering the goals and structure of the program, criteria for instructors, and incentives for faculty participation. Looking back, the decisions on structure and format appear simple and straightforward; but in the planning phase all possibilities were "on the table" so to speak, and active debates were underway. Following University Council approval of the FYO program, faculty members readily developed courses featuring their disciplinary interests; and a small stipend to teach these introductory courses sealed the deal. An abundance of course proposals meant some were not selected for inclusion in the program, much to the chagrin of the proposer.

The amazing array of FYO seminars can be seen by three titles, selected at random: Coffee Technology, Current Issues in Bioethics, and How Soccer Explains the World: An Unlikely Theory of Globalization. See https://fyo.uga.edu/BrowseSearchMain.aspx for spring 2014 courses and descriptions. Regular assessments provide information on student learning and point to areas in need of revisions. I imagine many future adjustments will be made as we continue to reshape and refine program and course goals and intended outcomes. The puzzle that remains, at least in my mind, is how to build on the FYO seminar across the four to five years of undergraduate education. What organizational structure would encourage full student engagement both in and outside of the classroom that is manageable, low in cost, and might yield significant outcomes. What outcomes might be most important?

My first thought was to launch capstone courses; and of assistance in this consideration was a recent issue of Peer Review (v. 15 no. 4, 2013), which focused on "Capstones and Integrative Learning." The issue describes capstone experiences at several colleges. In general, the

L. V. Morris $(\triangle)$

Institute of Higher Education, University of Georgia, 102 Meigs Hall, Athens, GA 30602-6772, USA

e-mail: lvmorris@uga.edu 
capstone is described as a senior-level or final-year integrative experience, which most often takes the form of an individual or group project, major paper, or thesis. The major purpose of capstones was reported as developing critical thinking and/or problem-solving skills; yet other goals such as career development, enhancing writing proficiency, and improving research skills were also mentioned. According to a 2011 NSSE study, capstone experiences were offered most often at smaller institutions; and the majority $(85 \%)$ were located in disciplinebased courses (Kinzie, p.27). The value of making the capstone interdisciplinary was noted by several of the authors, and a compelling case was made for this type of student experience. Some might question how much integration is occurring if the capstone is discipline-based, but complexity abounds when faculty members attempt to design courses and activities across programs and fields. Who gets the credit? Will it "count" in a program? Where will resources be found? Other such questions arise. In my experience, students find it easier to work across programs and work in interdisciplinary teams than do faculty members; but I will leave that for another day. Institutional policies and structure can be a challenge to us all!

As described in Peer Review, the Portland University capstone might serve as an inspiration for a similar experience at the University of Georgia (Kerrigan and Carpenter, 2013). At Portland, the capstone is a six-credit hour, interdisciplinary course where a student group serves a community member. All 4,000+ senior students are required to participate, leading to more than 400 capstones each year. UGA would need to plan for a similar number of students if we required a capstone; and, of course, we would need to identify the number of disciplinary capstones that are currently underway and not desire to shift to a new plan. Our real alignment with the Portland model would be around the focus on developing a "final product that serves the partner's mission." UGA currently has a large and well-respected service learning program with more than 150 three-credit hour courses that are "enhanced with service learning" (http:// servicelearning.uga.edu/index/). In 2012-13 these courses reached 6,500 students, and more than a dozen service learning courses were offered in study-abroad contexts. Faculty members who have experience with service learning at UGA would be a prime audience for discussions of a service learning capstone for all that is interdisciplinary. While the FYO looks at being successful in the collegiate experience, the senior year NYO (Next Year Odyssey?) could focus on the motto Non satis scire- "To Know is Not Enough", which I learned by reading in the Peer Review issue is Hampshire College's motto. We could start small, perhaps building the NYO program through partnerships between two or more of our 17 schools and colleges. Small grants for curricular development across the summer term could get the ball rolling. As a land-grant institution, UGA has established as a priority service and outreach to the public. What better way to equip the next generation of graduates than to formalize a public service orientation during the last stages of the undergraduate career? I do not think a capstone will make the connection from first-year seminar to final year seminar, but it could be a start. I will give this more thought. I hope you will, too, within your context.

\section{References}

Kerrigan, S., \& Carpenter, R. (2013). Culminating a college education while fostering civic agency. Peer Review, 15(4), 16-19.

Kinzie, J. (2013). Taking stock of capstones and integrative learning. Peer Review, 15(4), 27-30. 